\title{
Mayo del 68 y sus interpretaciones*
}

\author{
May 68, it's Interpretations
}

\author{
Juan Gabriel Gómez Albarello ${ }^{\mathrm{a}}$ \\ Universidad Nacional de Colombia, Colombia \\ jggomeza@unal.edu.co \\ ORCID: https://orcid.org/0000-0001-9097-763X
}

DOI: https://doi.org/10.11144/Javeriana.papo25.mdsi

Recibido: 04 Septiembre 2018

Aceptado: 03 Abril 2019

Publicado: 29 Junio 2020

\section{Resumen:}

Mayo del 68 ha sido caracterizado e interpretado de muchas maneras. En este artículo doy cuenta de tres de las caracterizaciones más importantes: una crisis política, un psicodrama y un carnaval, así como una crisis de la civilización. También señalo las razones por las cuales creo que Raymond Aron tiene razón en la mayoría de sus planteamientos acerca de lo ocurrido hace 50 años, y hago referencia a las razones por las cuales el legado de Mayo del 68 sería imposible de reclamar. Sin embargo, sostengo que la crítica antijerárquica de los estudiantes parisinos requiere ser tomada mucho más seriemente. Para ello, reflexiono sobre los planteamientos del neurocientífico Henri Laborit.

Palabras clave: Mayo del 68, crisis política, psicodrama, crisis de la civilización, Raymond Aron, Henri Laborit.

\begin{abstract}
:
May 68 has been characterized and interpreted in many ways. In this paper I provide an account of three characterizations among the most important: a political crisis; a psycho-drama and a carnival; and a crisis of civilization. I also provide the reasons making me thinking that Raymond Aron is right in most of his contentions about what happened 50 years ago. I also explain the reasons why the May 68 legacy would impossible to claim. However, I contend that the anti-hierarchical criticism by the Parisian students must be taken more seriously. To do so, I make some reflections on the arguments by neuroscientist Henri Laborit.
\end{abstract}

Keywords: May 68, political crisis, psycho-drama, crisis of civilization, Raymond Aron, Henri Laborit.

A miles de kilómetros y cincuenta años de distancia, ¿quién más quiere volver sobre Mayo del 68? Ya hay bastantes páginas dedicadas a un episodio histórico que parece estar sobreinterpretado. Sin interpelar directamente a los involucrados, lo más que se puede hacer es reconstruir muy esquemáticamente los hechos e interrogar las tantas interpretaciones que se hicieron de ellos, para aceptar como plausible aquella que mejor parezca darles sentido. Desde luego, este se revela desde el lugar y el tiempo en el cual preguntamos por él. Por tanto, quizá la manera más honesta de plantear la pregunta acerca de lo ocurrido hace 50 años en las calles de París sería, pues, ¿qué sentido puede tener Mayo del 68 en la actualidad?

Todavía es necesario añadir algo que justifique la pertinencia de la anterior pregunta. Esa justificación tiene que ver con el lugar común de que en un mundo globalizado todos los grandes eventos nos interpelan, de un modo en el cual hace ya más de doscientos años, en un mundo mucho menos global, Antonio Nariño ${ }^{1}$ se sintió interpelado por la Revolución Francesa. El problema es que, de partida, uno tiene que señalar qué es lo grande de Mayo del 68, y ya en este punto comienzan todas las dificultades para determinar su significado.

De acuerdo con una taxonomía de interpretaciones elaborada poco tiempo después de ocurridos los hechos, Mayo del 68 ha sido visto de todas las siguientes maneras: un complot para derribar el gobierno; una crisis de la universidad; una revuelta juvenil, que se desvaneció cual acceso de fiebre; una revuelta espiritual, que puso de presente la crisis de la civilización occidental; un conflicto social, que involucró un movimiento de nuevo cuño; un conflicto social, de tipo tradicional; una crisis política y, finalmente, un encadenamiento

Notas de autor

a Autor de correspondencia. Correo electrónico: jggomeza@unal.edu.co 
azaroso de circunstancias (Bénéton y Touchard, 1970). Unos años más tarde, con una forma muy francesa de conceptualizar las contradicciones históricas, Raymond Aron (1977, p. 412) describe lo ocurrido como un fracaso social, producido por el éxito económico.

Las páginas que Edgar Morin (1986) y Cornelius Castoriadis (1986) escribieron sobre Mayo del 68, autores que tienen un punto de vista muy distinto del de Aron, dan lugar a que uno piense que lo ocurrido ese mes está expuesto a la exageración: pareciera que la mayoría de sus partícipes y testigos más inmediatos querrían que aceptemos que lo ocurrido ha tenido unas implicaciones mucho más profundas de las que aparentemente podemos constatar. Aunque a la vista está el fracaso de una revolución que no fue, uno siente que le quieren convencer de que si no ha visto los efectos de Mayo del 68 en su vida, es porque no ha querido ver. En otras palabras, de que, si uno indaga con más cuidado, podría entonces darse cuenta de que muchas grandes transformaciones sociales se derivaron de aquel gran momento histórico.

Voces críticas de Mayo del 68 coinciden en esto último, pero de un modo negativo, pues le atribuyen haber desencadenado el hedonismo individualista, la fragmentación de las luchas emancipatorias y la legitimación política de la contracultura (Lipovetsky, 1986a, 1986b; Julliard, 2013), así como la emergencia de un pensamiento críptico, pedante y políticamente paralizante (Ferry y Renaut, 1990). ${ }^{2}$ Con respecto a esto último, a mí me persuade que el posmodernismo sea visto como una patología filosófica asociada a Mayo del 68, esto es, como una suerte de desorden de estrés postraumático de intelectuales cuyos anhelos revolucionarios quedaron pulverizados con el fracaso de la revuelta estudiantil y el fin de una huelga general. ${ }^{3}$ Sin embargo, me cuesta darle crédito a la idea de que esa revuelta haya sido el catalizador de una transformación político-cultural negativa, por la sencilla razón de que esa transformación ha tenido lugar en muchos lugares donde la revuelta estudiantil nunca provocó una crisis política como la ocurrida en Francia.

\section{Un resumen esquemático de los hechos}

¿Qué ocurrió durante ese mes admirable? De todas las interpretaciones de Mayo del 68, yo destacaría las cuatro siguientes: las de los sociólogos Raymond Aron (1968a; 1968b) y Mattei Dogan (1984), la del líder estudiantil Daniel Cohn-Bendit (1968), escrita junto con su hermano Gabriel, ${ }^{4}$ así como la del reportero de The Economist Daniel Singer (1970). Los dos primeros expresan alivio ante el fracaso del intento revolucionario; los últimos, decepción por la revolución que no fue. A pesar de su diversidad, estos autores tienen en común preocuparse por establecer una secuencia de los hechos con el fin de entender qué sentido tienen. Esto los separa de la gran mayoría de quienes los dan por sentado y se ocupan casi exclusivamente de su significado. Al respecto cabe observar que a Mayo del 68 le ocurre lo mismo que a muchos best-sellers y a muchos clásicos reeditados como best-sellers: ¡ mucha gente habla dando por supuestas muchas cosas, pero sin hablar de las cosas mismas! Por tanto, conviene ir a los hechos antes que a las interpretaciones.

Se me objetará, seguramente, que todo recuento supone ya una interpretación, por lo cual nunca podríamos ir más allá del conflicto de interpretaciones. Yo difiero. Uno puede tomar nota de las diferencias en las secuencias que establece cada autor, pero eso no significa que no exista un mínimo conjunto de hechos sobre los cuales versan las interpretaciones en conflicto. Así, pues, conviene recapitular lo ocurrido, lo que ningún historiador dejaría por fuera de una descripción de los eventos.

Mayo del 68 comenzó en marzo del mismo año, cuando un grupo de estudiantes logró canalizar las demandas antiautoritarias de reforma a la vida universitaria mediante formas de acción más o menos espontáneas, que no estaban en el libreto de la izquierda marxista-leninista. En esas formas de acción, y en varias de las consignas que se hicieron populares, es posible ver la influencia de los pensadores situacionistas Guy Debord y Raoul Vaneigem, del movimiento anarquista holandés Provo y también del grupo de marxistas heterodoxos que confluyeron en la revista Socialisme ou Barbarie. Como en muchos otros lugares del mundo, esos estudiantes estaban alucinados por la Revolución Cubana, la Revolución Cultural china y la Guerra 
en Vietnam. La gran mayoría estaba, sobre todo, en contra del código de conducta sexual tradicional, el hacinamiento en las clases, los métodos pedagógicos desuetos y la arbitrariedad del sistema de exámenes.

La sede de Nanterre de la Universidad de París fue donde comenzó todo. Luego de una protesta ocurrida el 22 de marzo, los estudiantes de segundo año de sociología decidieron poner en cuestión los exámenes y llenar las paredes de eslóganes que le dieron un tono inédito a las protestas: "Profesores, ustedes son cosa del pasado y también su cultura", "En el examen, responda con preguntas", "Cuando salga del Partido Comunista, déjelo tan limpio como lo encontró al entrar". Una de las acciones de esos estudiantes fue tomarse el auditorio principal, lo cual motivó al decano a cerrar la sede universitaria durante el fin de semana previo al inicio de los exámenes. A la semana siguiente, temiendo nuevos disturbios, el decano decidió cerrar otra vez Nanterre.

Este fue, podría decirse, su Florero de Llorente. Con reacción al cierre, el 3 de mayo varios estudiantes de Nanterre y de la Sorbona decidieron ocupar esta última sede, pero fueron desalojados por la policía. Al final del día, casi seiscientos estudiantes fueron detenidos y posteriormente obligados a comparecer ante una comisión disciplinaria. La reacción de la policía fue calificada de desmesurada, no solamente por grupos de estudiantes sino también por grupos de profesores e incluso por directivas que vieron en los hechos un ataque a la institución misma de la universidad. De aquí en adelante tuvieron lugar numerosos choques con la policía, siendo el más memorable la llamada "Noche de las Barricadas" el 10 de mayo en el Barrio Latino. A pesar del carácter violento de esos choques, no hubo ningún muerto.

Los estudiantes se ganaron la simpatía del público. Con el fin de reducir la presión sobre el gobierno, el primer ministro George Pompidou anunció el 11 de mayo la reapertura de las sedes universitarias. Sin embargo, la convocatoria hecha por dos confederaciones sindicales a una huelga general y a una marcha el 13 de mayo en apoyo de los estudiantes escaló el conflicto insospechadamente. ${ }^{5}$ Con posterioridad a la marcha, en varias fábricas grupos de trabajadores se declararon en huelga. Se estima que, hacia el 17 de mayo, el número de trabajadores que se había tomado las fábricas llegaba a los doscientos mil, que en solo cinco días ascendió hasta llegar a los diez millones. Puede decirse que tales huelgas fueron espontáneas pues su número creció por un efecto de contagio y no como resultado de una estrategia previa, coordinada por una confederación sindical o un partido político. Antes bien, lo ocurrido mostraba la pérdida de control de la situación por parte de las organizaciones sindicales y partidistas. Durante esos días, además, los estudiantes pasaron de organizar largas discusiones acerca de la reorganización de la universidad a promover discusiones de todos los ciudadanos acerca de la transformación de la sociedad. Luego de tomarse los auditorios de las diferentes sedes universitarias, los estudiantes ocuparon el emblemático teatro Odéon, al cual convirtieron en un foro permanente de discusión.

Todo esto era una situación sin precedentes. Los estudiantes que habían iniciado las protestas creían entonces que habían entrado en una etapa revolucionaria, que tendría que ser decidida por la acción de los trabajadores. Así lo afirmó Daniel Cohn-Bendit en la entrevista que Jean-Paul Sartre le hizo para Le Nouvel Observateur el 20 de mayo:

[El movimiento] ha tomado una extensión que no podíamos prever al inicio. El objetivo ahora es derrocar el régimen, pero no depende de nosotros [los estudiantes] que esto se logre o no. Si fuera realmente el objetivo del Partido Comunista, de la CGT [la Confederación Sindical Comunista] y de las otras direcciones sindicales, no habría problema: el régimen caería en quince días pues no puede hacer una manifestación que pueda oponer a la prueba de fuerza apoyada por todo el movimiento obrero. ${ }^{6}$

El 24 de mayo, el presidente de la república, Charles de Gaulle, en un discurso transmitido por televisión, anunció que convocaría a un referéndum en el que sometería a aprobación popular la autorización al mismo presidente para que reformara la universidad. Simultáneamente, el ministro de Asuntos Sociales convocó a las confederaciones sindicales a negociar un aumento salarial con el cual se le pudiera dar fin a la huelga general. Los llamados Acuerdos de Grenelle del 27 de mayo preveían un aumento del 35\% del salario mínimo y del $10 \%$ para todos los demás salarios. Ninguna de las iniciativas del gobierno prosperó. El discurso de de Gaulle cayó en el vacío, y las bases sindicales rechazaron las decisiones de sus dirigentes. 
La incertidumbre dio paso a la sensación de que el gobierno francés estaba por caer. Si bien el primer ministro Pompidou había sobrevivido a una moción de censura en la Asamblea Nacional la semana previa, la convicción de la izquierda no comunista era que la situación solamente podría resolverse instalando un gobierno provisional, en el cual también tuviera asiento el Partido Comunista. Los adalides de la iniciativa, François Mitterrand y Pierre Mendès-France, desafiaron de ese modo la que era una regla no escrita del funcionamiento de las llamadas democracias occidentales, pero sobre todo pusieron en cuestión el procedimiento constitucional de sucesión de los gobernantes. Por su parte, el gobierno comenzó a contemplar seriamente el escenario de una represión violenta de los insurrectos, involucrando en la friega al Ejército. La duda, sin embargo, carcomía al presidente de la república, Charles de Gaulle. Exhausto, este canceló el Consejo de ministros, citado el día 29, y partió sin rumbo conocido. Ni siquiera el primer ministro Pompidou sabía a dónde había ido el presidente. Varias horas más tarde se supo que se había entrevistado con el General Jacques Massu, comandante de las unidades francesas estacionadas en Baden-Baden, Alemania.

Los indicios disponibles sugieren que de de Gaulle estaba dispuesto a capitular. El presidente de la república había llegado a la base militar francesa con su familia y con su archivo personal; su esposa, con sus joyas. Este no era un gran tesoro, pero era su tesoro, por lo cual resulta creíble que los de Gaulle dejaron el país convencidos de que quizá no regresarían. Massu, sin embargo, persuadió al presidente de que este podía resolver la situación. Al día siguiente, el 30 de mayo, de Gaulle regresó a París y dio un nuevo discurso a la nación por televisión (de Gaulle, 1968). Anunció que no se retiraría y que mantendría también al primer ministro Pompidou. Echó atrás la propuesta de referendo, disolvió la Asamblea Nacional y convocó a elecciones legislativas. Amenazó con recurrir a medidas represivas en caso de que los grupos asociados a la que llamó la iniciativa totalitaria impidieran a los estudiantes estudiar, a los profesores enseñar y a los trabajadores trabajar y les dedicó una línea a los políticos que por ambición y odio sirvieron a esa iniciativa.

Un "Memorando de Inteligencia" del gobierno estadounidense hizo una evaluación sombría de la capacidad que tenía de Gaulle para resolver la crisis. No obstante, reconoció que había hecho una jugada que podía prosperar, pues el presidente contaba con dos recursos ciertos y uno potencial: el Ejército, la Policía a pesar de que sus sindicatos habían expresado simpatía por los trabajadores en huelga - y el público que, si bien había asumido una actitud pasiva ante la ruptura del orden, muy probablemente respaldaría al gobierno con el fin de conjurar el espectro de una guerra civil. El "Memorando" también incluyó una estimación de las opciones de los partidos de izquierda, los cuales habían quedado enfrentados a un dilema: intentar asumir el liderazgo de la revolución en curso o consolidar su imagen de fuerzas moderadas mediante el apoyo al orden y el cambio pacífico. Todo dependería de que la mayoría de los trabajadores regresaran a sus puestos de trabajo. En tal caso, esos partidos tendrían mucho más que perder, por lo cual recularían y volverían a los cauces establecidos (Departamento de Estado de los Estados Unidos, 1968). ${ }^{7}$

Para perplejidad de muchos de los involucrados, el Partido Comunista y su confederación sindical respondieron positivamente a la iniciativa de de Gaulle. Al aceptar la convocatoria a elecciones y darle fin a la huelga, la crisis política podía darse por terminada. La primera parte de la proposición estaba clara; la segunda, menos. No obstante, con el correr de los días, la resistencia espontánea de los trabajadores dio paso a la aceptación de las mejoras salariales y, fundamentalmente, del orden político y social. En las fábricas en donde se empeñaron en resistir, intervino la policía. Los estudiantes continuaron movilizados por su cuenta y acuñaron el lema, "Elección/Traición", pero de ese modo perdieron la sintonía que habían tenido con la mayoría de la sociedad. La estocada final fue el decreto del 12 de junio, mediante el cual el gobierno declaró ilegales a casi una decena de organizaciones de izquierda, incluido el Movimiento 22 de Marzo, liderado por Cohn-Bendit. La primera ronda electoral tuvo lugar el 23 de junio y la segunda el 30. Al final, el partido gaullista obtuvo el $46,4 \%$ del voto popular, pero por las características del sistema electoral francés terminó con el $72,7 \%$ de los escaños en la Asamblea Nacional. De ese modo, la revuelta de Mayo quedó definitivamente liquidada. 


\section{Mayo del 68 como una crisis política}

Del anterior recuento uno puede pasar inmediatamente a la interpretación de lo ocurrido en los términos de una crisis política. A juicio de Raymond Aron (1968 a esta crisis lo fue, en primer lugar, de los partidos políticos y de las organizaciones sociales, pues tanto los unos como las otras fueron incapaces de canalizar las demandas desbordadas de los estudiantes, así como su eco en los trabajadores, dentro de los cauces establecidos. En efecto, de una reforma a la universidad los estudiantes pasaron rápidamente a la crítica de la sociedad industrial capitalista, de la sociedad de consumo y también del orden sexual patriarcal. Se plantearon la transformación de la sociedad mediante la movilización espontánea, pero siempre defirieron en la clase trabajadora la cuestión de la toma del poder. La izquierda no comunista se planteó la ruptura del orden establecido, pero nunca logró persuadir a los comunistas de aceptar su liderazgo. Los comunistas, por su parte, denunciaron a los líderes estudiantiles como anarquistas, aventureros e irresponsables, pero se vieron en grandes dificultades para hacer que sus bases se reconciliaran con una forma de proceder más moderada. En lo que a los comunistas concierne, sin duda la gran pregunta es por qué no siguieron un curso de acción revolucionario en circunstancias en las cuales todo indicaba que se hallaban en una situación de ese tipo.

Cohn-Bendit (1968, p. 170 explica la moderación de los comunistas en términos del doble efecto producido por la lógica de burocratización de las sociedades industriales. Por un lado, esa lógica da lugar a la afirmación de la jerarquía en perjuicio de la autonomía de los individuos. Los partidos políticos, incluidos aquellos que proclaman tener un ideario revolucionario, no escapan a esa tendencia. Por tanto, no es de extrañar que contengan y condenen las iniciativas antijerárquicas de las bases, y se reconcilien con estructuras de poder opresivas. Por otro lado, esa lógica burocrática tiene una dimensión internacional: concierne a la relación establecida entre el Partido Comunista de la Unión Soviética y los partidos comunistas del resto del mundo. El Partido Comunista soviético fue el agente promotor de la lógica burocrática, que distorsionó el sentido de la Revolución Rusa. Luego de aplastar todos los focos independientes de resistencia, este partido convirtió a los movimientos comunistas fuera de Rusia en un mero apéndice de su política exterior. CohnBendit no ofrece evidencia en respaldo de esta afirmación, en buena medida porque eso era un hecho evidente. Bastaría citar el fuerte apoyo que le dio el Partido Comunista francés a la Unión Soviética con ocasión de la invasión a Hungría en 1956.

Con respecto a este último punto, Raymond Aron coincide con Cohn-Bendit. Aron, empero, destaca una faceta que Cohn-Bendit no considera detenidamente: el cálculo político que hicieron los comunistas. Según Aron (1968b, pp. 33-35), ${ }^{8}$ un curso de acción revolucionario habría implicado echar por la borda todo el esfuerzo que los comunistas habían realizado hasta entonces por entrar a la vida nacional como un partido con vocación de participar en una coalición de gobierno. Los dirigentes comunistas habrían razonado que solo una vez superada la crisis podrían tomar el liderazgo de la oposición contra de Gaulle. Esto es plausible justamente porque los grupos de izquierda más radicales habían impugnado el liderazgo de los comunistas y apelado a la acción espontánea de los trabajadores. Singer y Dogan aportan elementos que hacen pensar que la explicación más plausible, también sugerida por Aron, sea otra: la percepción de los comunistas de que la mayoría de la sociedad francesa no apoyaría un cambio revolucionario y, por tanto, que la crisis política se resolvería en su contra.

Singer conjetura que los dirigentes comunistas no apoyaron la propuesta de Mendès-France de constituir un gobierno provisional porque habrían quedado relegados al papel de socio menor en la transición. Sin embargo, a renglón seguido, Singer (1970, p. 192) enuncia otra hipótesis: que el gobierno de Mendès-France no habría sido capaz de ponerle fin a la crisis política y que, arrastrados por ella, los comunistas habrían sufrido con él su mismo destino. ${ }^{9}$ Esto coincide con la apreciación que hace Dogan de la posición que tomaron los dirigentes comunistas. Basado en una encuesta con una amplia batería de preguntas hecha poco tiempo después de la crisis, Dogan muestra que la mayoría del Partido Comunista era favorable a una insurrección 
popular, pero esa mayoría era una minoría dentro de la sociedad francesa. La gran mayoría no estaba dispuesta a involucrarse en una revolución y temía una guerra civil. El curso de acción más responsable de ese partido, tal como lo vieron sus dirigentes, era entonces continuar dentro de la órbita parlamentaria (Dogan, 1984, p. 272)..$^{10}$

Dogan hace otra apreciación acerca de la crisis política, que conviene tener presente. A su juicio, la convocatoria a elecciones fue el medio que le permitió a la mayoría silenciosa expresar su voluntad. En ausencia de ese medio, en todas partes resulta factible que agitadores minoritarios puedan hablar en nombre de la mayoría y procuren la ruptura del régimen representativo, ya sea por la vía de una insurrección militar o mediante un golpe militar. Las elecciones, por tanto, al permitir que la mayoría se exprese, obligan a los agitadores minoritarios a "retirarse a la sombra". A la luz de lo anterior, Dogan llega a la conclusión de que Georges Pompidou tiene el mérito mayor de que el régimen francés no se hubiese derrumbado. Con base en el testimonio de varios de los involucrados, Dogan subraya el pedido que varias veces le hiciera Pompidou a de Gaulle de convocar a elecciones, pedido que fue crucial el 30 de mayo. Pompidou estaba dispuesto a renunciar, si de Gaulle no incluía esa convocatoria en su discurso, como finalmente lo hizo (Dogan, 1984, pp. 273, 277).

Lo anterior podría resumirse, como en su momento lo recapituló Aron (1968b, p. 33), diciendo que la crisis política de Mayo del 68 se resolvió gracias a la "alianza objetiva” entre el gobierno francés y el Partido Comunista para evitar lo que los grupos que estaban a su izquierda llevaran a cabo "la solución revolucionaria". Por alianza objetiva hemos de entender el acuerdo tácito alcanzado por dos partes con intereses opuestos que, sin sentarse a dialogar, procuran una solución mutuamente beneficiosa.

\section{Mayo del 68 como carnaval y como psicodrama}

Aron (1968b) utiliza las dos expresiones referidas para caracterizar lo ocurrido en las discusiones promovidas por los estudiantes en los foros universitarios y en los foros espontáneos que tuvieron lugar en las calles, y de modo más general la actitud de los franceses durante los días en los cuales toda forma de autoridad parecía haberse desvanecido. Carnaval, sin duda, es un término peyorativo, pero es uno que captura el proceso de dislocación de los roles de los estudiantes y los profesores, que tuvo lugar en la primera parte del mes de mayo. Aron (1968b, p. 67; 2010, p. 619) refiere con indignación la idea de que los estudiantes aplicaron a la universidad el principio de autogestión de las fábricas, y menciona con igual rechazo las asambleas en las cuales se constituyeron comisiones ad hoc para definir el futuro de la universidad. En esas asambleas se decidió, por ejemplo, que los estudiantes tomaran parte en la definición del currículo e incluso en la realización de los exámenes, no meramente como evaluados sino también como evaluadores. Lo del currículo no era menor. De acuerdo con la idea de los estudiantes más radicales y de los profesores que les siguieron la cuerda la universidad sería puesta al servicio de la demolición de las estructuras sociales de dominación y su sustitución por nuevas formas de organización. A cuenta del hecho de que estas iniciativas eran promovidas por los grupos más radicales de izquierda, yo encuentro la aprensión de Aron más que justificada. Con una marcada intolerancia hacia todo aquello que no cuadraba con su ideario, el programa de refundación de la universidad de esos grupos tenía un carácter decididamente autoritario.

Psicodrama es otro término peyorativo, pero la forma en la cual Aron lo usa tampoco es desacertada. En los foros ciudadanos que tuvieron lugar en las calles, Aron dice haber visto, fundamentalmente, un gran desahogo, una expresión colectiva de todas las frustraciones de una población a la cual los niveles de confort alcanzados hasta entonces no le servían para darle a la vida ningún significado, ninguna razón de ser a la continuación del trabajo con el cual millones de individuos reproducían su existencia. Aron (1968b, p. 32) interpreta este psicodrama apelando a la idea de que el observador en este caso debe atenerse menos a los que dicen sus participantes y más a lo que sienten. La razón de ello es que resultaría improcedente darle importancia al contenido delirante de esos participantes pues ese contenido no conduce a ninguna parte, no permite 
entender nada. Aron (1968b, p. 115) justifica este procedimiento hermenéutico con base en el principio más general, según el cual, durante las revoluciones, es preciso prestar más atención al estado afectivo de los actores que a sus propósitos declarados. A este respecto, el sociólogo distingue entre lo que sintieron los estudiantes, los profesores y la mayoría de los ciudadanos que terminaron contagiados de la revuelta estudiantil y de las huelgas.

Puesto que todo comenzó con la revuelta estudiantil, conviene comenzar por considerar el estado de ánimo que Aron dice haber percibido en los estudiantes. El sociólogo distingue, por un lado, el caso de la mayoría, los no privilegiados, a quienes les devoraba la ansiedad de un futuro menos brillante que el prometido por la educación superior a la que nadie de su familia había llegado antes; ${ }^{11}$ por el otro, el caso de los estudiantes privilegiados, indignados por un sistema educativo reproductor de la desigualdad de oportunidades y desde el cual dirigieron una crítica global contra la sociedad (Aron, 1977, p. 414). No hay ningún estudio que confirme la asociación postulada por Aron entre estado mental y clase social. La encuesta hecha por el Instituto Francés de Opinión Pública, en septiembre de 1968, entre estudiantes universitarios y de colegio, confirma al menos que la motivación fundamental de la mayoría de los participantes en la revuelta estudiantil tenía que ver más con la ansiedad causada por los exámenes y con la reforma de la universidad que con la transformación de la sociedad. ${ }^{12}$

Con respecto a los profesores, Aron $(1977$, p. 420) juzga que hubo un sentido de capitulación moral ante las demandas de los estudiantes, lo cual aplicaría tanto a aquellos que de mala gana y con mala conciencia conciliaron con un modelo irrealizable de universidad, como a los profesores de izquierda que terminaron identificándose con esas demandas. En ello ve la convergencia de motivos ideológicos con motivos de la política universitaria e incluso con motivos estrictamente egoístas. En efecto, la revuelta estudiantil era una oportunidad para un nuevo balance de poder entre los profesores, las directivas y el Ministerio de Educación, e incluso para unos cuantos, el prospecto de una mejor carrera (Aron, 1968b, p. 143).

El caso de la mayoría de los ciudadanos es para Aron el más intrigante. En lo que irónicamente llamó la maratón de palabras, las conversaciones interminables que comenzaron en las asambleas estudiantiles y luego se extendieron a las calles de París, Aron vio desplegado el desahogo de las frustraciones, los resentimientos y las quejas de esa mayoría, pero con una particularidad, a su juicio, muy francesa. El sociólogo le imputa al pueblo francés ver magnificadas retrospectivamente todas sus revoluciones y considerarlas como una suerte de fiestas, en las cuales puede experimentar lo que su vida cotidiana le niega. Por cuenta de ese virus revolucionario, esa mayoría, dice Aron (1968b, p. 32), se abandonó a una "negación utópica de la realidad".

Conviene tener en cuenta que en este análisis de Aron hay un punto ciego, tanto político como metodológico. El pensador que siempre consideró necesario apreciar los hechos políticos con una fría lucidez no pudo dejarse de sentir implicado por el calor de los acontecimientos. En una temprana entrevista acerca de lo ocurrido en Mayo del 68, hecha por Claude Torracinta para la Radio Televisión Suiza, el 13 de junio de 1968, Aron (1968a) revela una postura comprometida contra la revuelta estudiantil y la huelga general. En esa ocasión, dijo:

De partida, quisiera hacer una confesión: no creo que hoy yo soy un objetor [lapsus que inmediatamente corrigió], un observador objetivo. Pienso que he vivido estas semanas inmerso en un sentimiento de cólera, de indignación tal que soy incapaz de hacer lo que yo trato de hacer ordinariamente, esto es, ver fría y lúcidamente lo que ha ocurrido. (La traducción es mía; las cursivas, también)

Es inevitable tomar esta declaración como una confesión de parte, una según la cual el intérprete nos revela sus propias limitaciones. Ofuscado por su propia implicación en los eventos, Aron nunca consideró seriamente el efecto político que haya podido tener la participación de los parisinos en las conversaciones políticas espontáneas que él describe como la maratón de palabras.

La ofuscación, sin embargo, no surge solo de su implicación en los eventos, sino también de una manera de considerar lo político estrictamente en los términos de quién obtiene qué, dónde y cómo. En efecto, en 
el análisis de Aron poco peso tiene la forma en la cual los sujetos se constituyen en el espacio político, la manera en la cual se identifican a sí mismos y el efecto que adquiere en su vida tal proceso de constitución e identificación. ${ }^{13}$ Aunque no hicieron una revolución, los ciudadanos que se implicaron mutuamente en esas conversaciones espontáneas se cambiaron a sí mismos de una forma tan duradera que eso ha hecho de Mayo del 68 un punto de referencia fundamental en su práctica cotidiana. Tal es la conclusión que uno puede sacar del registro de la experiencia de un buen número de los participantes.

Por ejemplo, Jean-Pierre Fournier (Abidor, 2018, p. 94), estudiante de colegio, tenía 16 años, cuando ocurrieron los eventos de Mayo. Dice,

Algo que me impactó mucho más que todas las marchas, que me fascinó y que conservo conmigo, fue la atmósfera de discusión general en las calles, en la que los carros ya no circulaban, y recuerdo que cerca de [el colegio] Condorcet había grupos de personas, el vecindario alrededor de Saint-Lazare era y sigue siendo un vecindario lleno de oficinas, bancos, compañías de seguros, y la gente salía a las calles a hablar. Era la primera vez que lo veía, gente de todas las opiniones hablando junta. (La traducción es mía)

Fournier trabaja en la actualidad como administrador escolar y ha sido voluntario de Educación sin Fronteras.

Suzanne Borde era estudiante universitaria de primer año, y tenía 24 años cuando se involucró en las protestas estudiantiles. No tenía ninguna formación política previa. Si bien no tomó parte en las marchas y las confrontaciones con la policía, le atrajo a participar el tipo de discusión que tenían lugar en el seno de los llamados Comités de Acción (CA). Según Borde (Abidor, 2018, pp. 77-78), ella se involucró por las discusiones permanentes,

donde todos expresaban sus pensamientos acerca de lo que estaba pasando, cómo veíamos la vida. Y esto me cambió por completo, cambió mi forma de pensar. Hasta entonces no tenía conciencia política ni idea de lo que sería mi vida...incluso en los CA, donde había personas con una formación más profunda que la que yo tenía, me escuchaban. Pero me impresionaron, eran personas que tenían ideas bien estructuradas. No siempre los seguí, pero los contradije, cuando no estaba de acuerdo. Y así desarrollé mi propia voz. (La traducción es mía)

En lo que Aron tiene razón es en el hecho de que esta nueva subjetividad política nunca logró constituirse en una alternativa clara de cambio político. El impacto que tuvo en el marco institucional de la sociedad fue nulo. Ni los canales institucionales de formación de la voluntad colectiva ni la regulación de la vida económica sufrieron una alteración sustancial. De allí que los eventos de Mayo del 68 puedan ser interpretados en los términos de un desahogo, de un psicodrama sin mayores consecuencias uno que, sin embargo, ha devenido en objeto de culto entre los intelectuales que se sintieron implicados por ellos (Aron, 2005, p. 363), y también en los que después buscan inspiración en él para promover un cambio radical del orden social.

\section{Mayo del 68 como crisis de la civilización}

Poco después de resuelta la crisis política, el entonces ministro de Cultura de Francia, el escritor André Malraux (1968), pronunció un discurso en el cual se refirió a los eventos de mayo en los términos de "crisis de la civilización”. Malraux aludió al hecho de que la revuelta estudiantil era un fenómeno común a muchos países muy diversos entre sí, por lo cual debía ser tomada como evidencia de una crisis global. Esa crisis tendría que ver con el carácter específico de la civilización moderna: proclamarse heredera de todas las civilizaciones que la precedieron, tener un fundamento secular y promover transformaciones tecnológicas que han terminado por transformarnos a nosotros mismos. Por tanto, sería totalmente inadecuado pensar que la reforma universitaria apaciguaría la revuelta estudiantil. A juicio de Malraux, la raíz del problema era mucho más profunda. Lo que Mayo del 68 le mostró a los involucrados y también a los testigos de la revuelta fue "la conciencia del fin de un mundo. Incluso con salarios crecientes, nuestra sociedad aún no está adaptada a la civilización de las máquinas". 
En un primer momento, el sociólogo Raymond Aron (1968b, p. 16) pronuncia un juicio agnóstico acerca de esta valoración de lo ocurrido. Señala que los estudiantes quizá expresaban un malestar que afectaba el conjunto de la civilización, pero a renglón seguido observa que con su actitud libertaria estaban preparando el camino para la ruina de las libertades, de las cuales las universidades continuaban siendo su garante. Más que agnóstico, con la disyuntiva "psicodrama o fin de una civilización", Aron (1968b, p. 19) da a entender que el significado de los eventos de Mayo del 68 fue exagerado grandemente. De un modo igualmente provocativo y desdeñoso, Aron se expresa en su trabajo posterior sobre el estado político y cultural de la Europa occidental. La pregunta retórica de si era necesario transfigurar los desórdenes protagonizados por los estudiantes y bautizarlos gloriosamente "crisis de la civilización" (Aron, 1977, p. 415) puede ser interpretada como evidencia de que el sociólogo nunca se tomó en serio el planteamiento de Malraux ni el de otros tantos que vieron en Mayo del 68 el síntoma de la crisis de Occidente o el heraldo de un nuevo orden.

Repetidamente, Aron expresa su negativa a la posibilidad de comprender los eventos de Mayo del 68 por medio de una explicación sociológica. Siempre creyó que, a lo sumo, se podía hacer un relato de los hechos que diera cuenta de la forma en la cual una revuelta estudiantil, sumada luego a una huelga general, de un modo singular había dado lugar a una crisis política en Francia (Aron, 1977, p. 409; 2010, p. 626). Sin embargo, reconoció que la revuelta estudiantil había mostrado la fragilidad de las instituciones y, de modo general, del orden social (Aron, 1968b, pp. 14, 44; 1977, p. 412). Si bien en otras latitudes el rechazo a las jerarquías no dio lugar a una crisis política, ese rechazo sí era susceptible de un análisis sociológico, que aplicaría incluso a los eventos de Mayo del 68. Aron refiere por lo menos cinco mecanismos que contribuyen a explicar el desahogo de los franceses en la maratón de palabras y también en los muros de la ciudad. Los tres primeros son de estirpe tocquevilliana: el efecto de la individuación de las personas en la sociedad moderna, la debilidad de los grupos intermedios y la radicalización de las demandas, cuando la situación mejora. El cuarto mecanismo, de estirpe weberiana, concierne a la despersonalización de la sociedad moderna, y el quinto, la contradicción entre la igualdad política y la desigualdad económica, es de estirpe marxista.

Aron encuentra en la pérdida del consenso religioso y la erosión de las formas tradicionales de autoridad, una de las causas de la revuelta estudiantil. Estos fenómenos serían un efecto de lo que Tocqueville (1850) diagnosticó en su obra La Démocratie en Amérique (capítulo V de la primera parte del Tomo II) como la difusión del espíritu igualitarista de la democracia. Aron (1977, pp. 421-438) retoma esta tesis, pero la modifica, a la luz del hecho de que esa erosión es observable incluso en sociedades totalitarias. Por tanto, atribuye la erosión de la autoridad de la familia, la Iglesia, la universidad y el estado al efecto de lo que de manera críptica denomina "el progreso de las ideas y los eventos". ${ }^{14}$

Un tema fundamental de La Democracia en América es el papel moderador de las asociaciones civiles, a las que Aron llama los grupos intermedios. En la perspectiva de Tocqueville, las asociaciones civiles son fundamentales para impedir que el poder se concentre en el Estado, y para que los individuos no abandonen la esfera común ni la práctica de las virtudes cívicas. En la perspectiva de Aron (1968a, 1968b), esos grupos (los partidos y los sindicatos) deberían haber prevenido que los individuos se entregaran a desvaríos utópicos y, fundamentalmente, al deseo de darle a esos desvaríos una concreción política. Si los grupos intermedios hubiesen tenido un fuerte arraigo en la sociedad, los grupos radicales de estudiantes nunca habrían contagiado a los ciudadanos de participar en un proyecto irrealista y sin un objetivo fijo.

En vez de profundizar en este aspecto de la sociología tocquevilliana, Aron prefirió poner el énfasis en un tercer mecanismo, al cual denominó la "Ley de Tocqueville", cuyo efecto podría explicar no solo la insatisfacción de los trabajadores sino también la insatisfacción general de la sociedad. Aron observa que los trabajadores habían mejorado sustancialmente sus condiciones en las fábricas y su estándar de vida, y contaban además con suficiente libertad para elegir sus líderes sindicales. Por tanto, su insatisfacción podría ser comprendida a la luz del mecanismo paradojal de que esa insatisfacción aumenta cuando las cosas mejoran (2010, p. 624). Aron (1977) aclara, sin embargo, que este mecanismo no da cuenta de la difusión del tópico de la "sociedad represiva", esto es, la convicción extendida entre los líderes de la revuelta estudiantil de que las 
sociedades occidentales sufren de formas de coerción más insidiosas y efectivas que las propias de sociedades no liberales.

La despersonalización de la sociedad es el cuarto mecanismo que daría cuenta de los agravios formulados tanto por los estudiantes como por el resto de los ciudadanos. Aron (1977, pp. 434-437) observa que, con el paso de sistemas fundados en un tipo de legitimidad tradicional a otros fundados en un tipo de legitimidad racional, los individuos se perciben a sí mismos atrapados y oprimidos por una racionalidad cuyo propósito desconocen. No es meramente el caso de que cada persona sea un engranaje más en la máquina industrial, sino que es toda la sociedad que obedece a leyes cuyos efectos escapan al control de los encargados de tomar decisiones. De allí que la revuelta sea contra el sistema, aunque sea este mismo el que proporciona las comodidades que las personas disfrutan. ${ }^{15}$

El último mecanismo al cual se refiere Aron (1977, pp. 442-446) es la contradicción entre la igualdad política y la desigualdad económica. A este respecto, el sociólogo observa que la propiedad privada de los medios de producción, el mercado y la desigual distribución del ingreso no gozan de la misma legitimidad que tienen los principios democráticos. En este contexto tiene lugar la demanda de mayor participación de los trabajadores en las empresas, incluso cuando esa participación choca con los imperativos de eficiencia sobre los cuales se asienta la empresa moderna. Esta demanda de participación va en contra, también, de la aceptación de jerarquías que, en su opinión, los liberales deberían defender como un presupuesto del funcionamiento de las sociedades. Según Aron, la clave está en la pluralidad de jerarquías, esto es, en las salvaguardas contra la concentración del poder de decidir acerca de la distribución del ingreso e incluso acerca de la calidad artística o literaria de una obra.

La revuelta antijerárquica fue, precisamente, uno de los contenidos centrales de la retórica de la izquierda no comunista durante Mayo del 68 y contra ella Aron (1968b, p. 14) dirigió sus más duras invectivas. ${ }^{16}$ En la lectura más sobria que hizo casi una década después, Aron encuentra factores que pueden explicar el delirio que vio en las calles parisinas, uno que puede ser tomado como evidencia de una crisis más general. En fenómenos aparentemente inconexos, como la reducción de la tasa de natalidad y la formación de sindicatos en el Ejército, Aron ve el síntoma de una civilización que se condena ella misma a morir por cuenta de un individualismo hipertrofiado; en el sentido libertario, pero antiliberal de los estudiantes de Mayo del 68, en su "prohibido prohibir", meramente la popularización de la crítica a la civilización industrial (Aron, 1977, pp. 412, 457).

\section{El legado imposible de Mayo del 68}

La ausencia de un modelo alternativo viable, que diera respuesta a los problemas tales como la contradicción entre igualdad y jerarquía, así como la despersonalización de la sociedad es lo que, a juicio de Jean Pierre Le Goff, convirtió a Mayo del 68 en un evento cuyo legado es imposible de reclamar. Según Le Goff (2002, p. 470), el movimiento estudiantil era el "portador de ideas y exigencias radicales que no permiten en absoluto darles respuestas constructivas sino, al contrario, dan lugar a descartarlas rápidamente”. Con todo, vale decir que la crítica a las jerarquías no carece de mérito. La demanda de participación de los afectados en la toma de decisiones que los afectan ha dado pie a innovaciones radicales en el ámbito de la cultura, como ha ocurrido en el caso de las orquestas sin director (Sabaneev, 1928; Khodyakov, 2007). No debería descartarse, por tanto, que innovaciones de ese tipo puedan darse en el ámbito de la economía, como de hecho ya se ha planteado (Seifter y Economy, 2001; Vredenburgh y He, 2003), e incluso en el ámbito de la política (Gómez Albarello, 2019). El mismo concepto de democracia participativa, valga la pena también recordarlo, fue acuñado en 1962 en el Manifiesto de Port Huron por una asociación de estudiantes, la Students for a Democratic Society (SDS), que se involucró activamente en las protestas de los años 1960 en los Estados Unidos (Flacks y Lichtenstein, 2015). 
Como sus compañeros al otro lado del Atlántico, la SDS también formuló una crítica radical a las jerarquías en lo político y en lo económico. Y, como esos compañeros, la SDS se mostró incapaz de ofrecer un modelo viable de toma de decisiones que pudiera servir como alternativa al orden partidocrático existente. Con decepción, Staughton Lynd, uno de los principales líderes de la SDS, reconoce que el gobierno representativo es necesario, una vez que una organización crece hasta alcanzar cierto tamaño. Esto quiere decir que toda organización de mediana o gran escala debe institucionalizar procedimientos de toma de decisiones que permitan tramitar las discusiones de un modo incluyente y a la vez eficaz. Por el contrario, insistir en tomar las decisiones por consenso, cuando un grupo es demasiado grande o diverso, es extender la invitación a una minoría para que se tome ese grupo. Tal cual fue lo que sucedió con la SDS: cayó en manos de grupúsculos sectarios, que con su canibalismo espantaron a la mayoría de estudiantes dispuestos a involucrarse activamente en la política (Lynd, 2010, p. 104). Lo mismo le sucedió al movimiento estudiantil en Mayo del 68. Alain Geismar, a la sazón un joven profesor, y junto con Cohn-Bendit, uno de los líderes más importantes del movimiento de entonces, hace una observación similar: "El movimiento fue devorado por las ideologías militantes". (Cohn-Bendit et al., 2018, p. 347) Por tanto, puede uno concluir que, si los estudiantes a ambos lados del Atlántico no pudieron resolver sus diferencias internas y conseguir relevancia política, menos iban a poder ofrecer un modelo viable de organización social.

Según Le Goff (2002, p. 471), hay una razón fundamental por la cual los protagonistas de Mayo del 68 no ofrecieron una resolución adecuada a la contradicción entre igualdad y jerarquías: por un lado, haber erigido la autonomía individual en un absoluto; por el otro, haber asimilado toda forma de autoridad y de poder a un medio de dominación. Lo primero suponía abrazar una concepción de la naturaleza humana equivalente a la caricatura roussoniana de los seres humanos nacidos buenos y pervertidos luego por la sociedad. Ninguna otra premisa sirve a la tarea de justificar la expresión incondicionada de los deseos de los individuos. ${ }^{17}$ Lo segundo implicaba asumir una visión del poder político según la cual este es una entidad homogénea y opresiva, de la cual se puede prescindir, pues los individuos pueden coordinar sus acciones por medio del diálogo, sin ninguna mediación institucional. De ahí que Le Goff (2002, p. 465) afirme,

\footnotetext{
Hoy el mayor riesgo es "desear sin fin", llamar aún hoy a la juventud a rebelarse contra el poder y la censura, contra la escuela separada de la vida, contra el fascismo en ascenso y la "normalidad opresiva". Esta postura es de buen recibo en ciertos sectores de la izquierda y no se compromete a gran cosa excepto a estar del lado de los buenos en numerosos debates mediáticos y de la alta sociedad. Se sigue como si el Estado y las instituciones fueran tan sólidas y seguras de sí mismas, como si la escuela no funcionara sino a punta de vejámenes y humillaciones, como si la familia autoritaria y cerrada — completamente ordenada de acuerdo con la voluntad del padre - fuese siempre el modelo dominante. Extraña ceguera que se niega a ver las realidades que la importunan.
}

En un contexto como el colombiano, lo peor de este legado es que se funde con un repertorio cultural de resistencia a la autoridad, que tomó cuerpo durante la colonia española y que ha perdurado a lo largo de toda la vida de la república. Ese repertorio incluye justificaciones a excepciones de todo tipo al cumplimiento de las reglas, que erosionan la confianza interpersonal, dificultan la coordinación social y hacen extremadamente costoso el logro de objetivos comunes. ${ }^{18}$ Muchas de las personas que echan mano de ese repertorio no tienen la más remota idea de qué ocurrió en Mayo del 68. En lo que concierne al legado de esta "revolución que no fue" (introuvable, la llama Aron), el problema radica en los intelectuales que se identifican con ese legado y que proporcionan justificaciones adicionales de las infracciones cotidianas, amparándolas con referencias a un espíritu supuestamente libertario.

\section{Sean realistas, pidan lo imposible ${ }^{19}$}

¿Deberíamos concluir de todo lo anterior que no hay nada en Mayo del 68 que valga la pena, nada que amerite una reflexión adicional acerca de lo que ese evento puede significar hoy? En las páginas precedentes, 
continuamente le di crédito a la interpretación que hizo Raymond Aron de la revuelta estudiantil y del grado limitado en el cual dicha revuelta podría tomarse como indicativa de una crisis de la civilización. Sin embargo, en esta última sección quisiera comenzar por destacar lo siguiente: Aron descartó como utópicas y delirantes las demandas antijerárquicas de la revuelta estudiantil con la misma seguridad con que desdeñó el primer informe del Club de Roma, Los limites del crecimiento (Aron, 1977, p. 456). Este informe, no sobra recordarlo, contiene el primer modelo que plantea límites a la capacidad del planeta para satisfacer las necesidades de una población que crece continuamente (Meadows et al., 1972). Modelos posteriores han validado el planteamiento según el cual en este siglo la huella ecológica de la humanidad puede alcanzar niveles extremos, a tal punto que la vida llegue a ser insostenible, dando lugar incluso a una posible sexta extinción (Kolbert, 2014).

La incapacidad de la comunidad internacional para ponerse de acuerdo en una solución colectiva al problema del calentamiento global pone en evidencia el inadecuado funcionamiento de las jerarquías políticas y económicas. En efecto, grandes empresas que verían afectadas sus ganancias si se reduce drásticamente la producción y el consumo de energías de origen fósil se han opuesto sistemáticamente a las regulaciones con las cuales podríamos mitigar el calentamiento global. Los Estados, por su parte, han mostrado estar más preocupados por los niveles de crecimiento de sus economías que por la preservación del medio ambiente y el bienestar de las generaciones futuras (Rich, 2019). Esto le da razón al planteamiento del expresidente de Uruguay, José Mujica (2015, pp. 6, 22), según el cual la crisis ecológica es, en realidad, una crisis política. Por tanto, haríamos bien en pensar que, si Aron se equivocó en su previsión acerca de las posibilidades del crecimiento económico, entonces deberíamos tomar con un grano de sal su crítica a la revuelta antijerárquica.

El planteamiento radical de los protagonistas de la revuelta estudiantil es que ninguna transformación sustancial de la sociedad podrá llevarse a cabo, si las organizaciones que la promueven reproducen en su seno la dominación que pretenden abolir. En Obsolete Communism, Daniel Cohn-Bendit (1968, p. 250) hace un recuento de la revuelta estudiantil y de las ideas que la animaron. En ese libro, el autor dirige su crítica no solo contra la alienación y las desigualdades que genera el capitalismo y la despersonalización de la lógica burocrática del estado, sino también contra las organizaciones de la izquierda que reproducen esa lógica despersonalizadora y alienadora. Cohn-Bendit cuestiona especialmente al partido político, pues este funciona de acuerdo con una estructura jerárquica, que contiene el que a su juicio debería ser el flujo espontáneo y directo de los oprimidos en su lucha por un orden nuevo. De ahí que formule un heptálogo, un listado de siete principios que todo "movimiento del futuro" debería seguir. Este incluye la garantía de la pluralidad y la diversidad de todas las corrientes políticas en su interior; el libre intercambio de ideas y el libre flujo de información; la rendición de cuentas y la revocación del mandato de toda persona elegida por el movimiento; la lucha contra la formación de cualquier clase de jerarquía y la oposición a la especialización dentro de la organización; la abolición de la distinción entre trabajo intelectual y trabajo manual, y de la discriminación basada en el sexo de las personas; la dirección de las industrias y de las empresas por las personas que trabajan en ellas, y la superación de una ética basada en la renuncia y el sacrificio personales.

Aparentemente, la complejidad de la sociedad actual impediría que estos principios pudieran implementarse más allá de la escala de pequeños comités. La crítica a la separación entre trabajo manual e intelectual, así como a la especialización en el cumplimiento de tareas, iría en contravía de los principios que permiten que muchas organizaciones funcionen. No obstante, la crítica a las jerarquías no es del todo implausible. Henri Laborit (1976, p. 139) llama la atención al hecho de que la información técnica abstracta, que hace posible que funcionen las organizaciones con las cuales resolvemos problemas colectivos, podría ser ampliamente difundida. Es el acaparamiento de esa información lo que permite que grupos de individuos puedan explotar a los demás para su propio beneficio en todos los ámbitos. Este fenómeno es evidente en el ámbito económico, en el cual las empresas, e incluso los estados, luchan despiadadamente por tener acceso a la información con la cual podrían obtener mayores ventajas en la producción, circulación y distribución de bienes y servicios. Difundir ampliamente la información técnica abstracta no es un postulado utópico, como 
podría juzgarse a primera vista. Antes bien, es la premisa de muchas formas de economía colaborativa, que han tomado el lugar de formas de producción basadas en el lucro (Mason, 2015a).

Hay, sin embargo, un tipo adicional de conocimiento al cual todos los individuos deberíamos tener acceso: el conocimiento de nosotros mismos. Este nos daría a cada uno de nosotros la consciencia de que muchas veces factores afectivos toman el lugar del conocimiento necesario para la resolución de problemas comunes. Esos factores afectivos son de diversa índole; comprenden motivaciones pulsionales, deseos de dominación insatisfechos, búsqueda de satisfacciones narcisistas, aprendizajes culturales, etc. De allí que, según Laborit, sea más importante prestar atención a lo que impulsa el discurso y la acción de los individuos que al contenido de ese discurso y esa acción. Hacer caso omiso de esos factores afectivos es lo que permite que reproduzcamos continuamente sistemas jerárquicos de dominación. Abolir la alienación jerárquica sí sería posible, siempre y cuando la especie humana pudiera organizarse de un modo en el cual los individuos podamos tener acceso al conocimiento técnico y al conocimiento de nosotros mismos. Este último conocimiento es el que nos permitiría inventar nuevas relaciones sociales y formas de organización no opresivas.

Laborit no abriga ilusiones con respecto a la posibilidad de alcanzar semejantes logros. Puesto que concibe a los seres humanos en términos de la inercia de nuestras pulsiones, de la imagen que tenemos de nosotros mismos, de nuestro lugar en las diferentes jerarquías sociales y políticas, así como de nuestro aprendizaje cultural, Laborit asume que nuestra capacidad de elección es muchas veces más limitada de lo que estaríamos dispuestos a reconocer. Los graves problemas colectivos que tenemos que resolver - la alienación jerárquica y el nihilismo corrosivo, la creciente desigualdad material y la degradación medioambiental— demandan de nosotros la escogencia de una forma de vida diferente, de una civilización diferente. Si finalmente realizáramos esa escogencia, ella sería

dado el acceso al conocimiento, una cierta conciencia difusa de lo que es nuestro viejo comportamiento, nuestra tardía comprensión de los mecanismos que lo gobiernan, una nueva presión de necesidad a la cual debemos obedecer si la especie ha de sobrevivir. Ni siquiera es cuestión de si es bueno que la especie sobreviva, ni siquiera sabemos si sobrevivirá. Sin embargo, parece cierto que, para sobrevivir, su supervivencia implica una transformación profunda del comportamiento humano. Y esta transformación solo es posible si todos los seres humanos toman conciencia de los mecanismos que los hacen pensar, juzgar y actuar. (Laborit, 1976, p. 145)

Esto no es óbice para que emprendamos la tarea de definir un tipo de civilización diferente y de descartar un modo de vida que no parece ser sostenible en lo absoluto. En lo que concierne a la política, Laborit plantea de manera sumaria que la democracia es un engaño, pues detrás de discursos aparentemente lógicos están en juego factores afectivos como el narcisismo satisfecho o insatisfecho de los implicados en una contienda. La consciencia de este fenómeno nos debería motivar a realizar diseños institucionales que canalizaran esos factores afectivos de un modo más productivo para la sociedad.

El caso de la competencia electoral, una de las instituciones básicas del sistema político, es revelador de una dinámica bastante generalizada. Quienes se involucran en un proceso político competitivo de este tipo han de adquirir y desarrollar una serie particular de capacidades cognitivas y afectivas que muchas veces están en contravía del logro de objetivos comunes. Los participantes en la competencia electoral tienen que saber cómo financiar su campaña, cómo pedir y cobrar favores, cómo transmitir de un modo efectivo sus mensajes usualmente de la forma más simple posible- y cómo destruir simbólicamente a sus oponentes. ${ }^{20} \mathrm{~A}$ su turno, las capacidades cognitivas y afectivas de los ciudadanos tienden a ser reducidas a su mínima expresión. Las campañas políticas no son particularmente informativas de los problemas comunes. Antes bien, la dinámica competitiva tiende a degradar el conocimiento que tienen los ciudadanos, limitándolo a eslóganes y etiquetas, un fenómeno que Anthony Downs (1957, p. 244) denomina la ignorancia racional del votante, pues el costo de los ciudadanos de adquirir información acerca de los asuntos políticos es sustancialmente superior al beneficio de hacerlo, por lo cual resulta racional limitarse a los eslóganes y las etiquetas.

Estos problemas están agravados por la que parece ser una epidemia narcisista, consistente en la amplia difusión de rasgos de personalidad tales como baja empatía, poca preocupación por los demás y excesiva 
preocupación por uno mismo, un creciente individualismo y una baja conciencia colectiva (Twenge y Campbell, 2009). Según Jerrold Post (2015, p. 10), esta epidemia parece haber alcanzado proporciones pandémicas entre los políticos. Esto no significa que todos los políticos sean narcisistas, sino que "el ámbito del servicio público y su primer plano son particularmente atractivos, incluso irresistibles, para los individuos con tendencias narcisistas". Políticos con una personalidad narcisista maligna, a su vez, contribuyen a activar fenómenos de narcisismo colectivo, esto es, un compromiso emocional con creencias relativas a la superioridad del propio grupo, sea este una nación o un partido (Golec de Zavala et al., 2009; Volkan, 2004).

Enfrentar la epidemia narcisista y, en particular, la pandemia narcisista en la política requiere de muchos esfuerzos. Estos no pueden limitarse a diseños institucionales, pero tampoco pueden prescindir de ellos. La razón radica en el hecho de que las instituciones proporcionan incentivos de diverso tipo a la adquisición, así como al abandono, de disposiciones cognitivas y afectivas, tanto entre los elegidos como entre los ciudadanos. No hay duda alguna de que la democracia directa no será nunca un sustituto de las instituciones representativas. El modelo de democracia participativa que propusieron los líderes de la Students for a Democratic Society tampoco es una alternativa adecuada. Sin embargo, deberíamos tomarnos muchísimo más en serio la crítica a las jerarquías que articularon los estudiantes al lado y lado del Atlántico norte.

En sus inicios, los partidos verdes europeos encarnaron la revuelta antijerárquica en su estructura interna. Muchos de ellos adoptaron principios tales como la paridad de género, el mandato imperativo y la rotación en los cargos como un antídoto a la tendencia a la profesionalización propia de toda organización que se involucra en la dinámica electoral. Sin embargo, con excepción de la paridad de género, estos principios fueron progresivamente relajados e incluso abandonados (Rihoux, 2016). En la actualidad, incluso los partidos verdes europeos parecen haber perdido su vocación transformadora, algo que Daniel Cohn-Bendit (2013, p. 20) ha subrayado críticamente. ${ }^{21}$ Por su parte, estudiosos de la dinámica electoral europea, como Peter Mair (2013), han destacado el fenómeno de la pérdida de confianza de la ciudadanía en los partidos, así como la erosión de los vínculos de estas organizaciones políticas con las organizaciones sociales. Todo esto puede verse bajo el prisma de las consecuencias negativas que ha tenido la profesionalización de la política y la necesidad de encontrar un modelo de representación política que no esté mediado por los partidos. Este modelo podría ser el sorteo. La selección aleatoria de los ciudadanos para que sirvan como representantes no solo permitiría que la sociedad representada se reflejara mejor en esos representantes. En conjunción con la rotación, también contribuiría a liberar las jerarquías políticas de la carga narcisista competitiva que vicia su funcionamiento. ${ }^{22}$

En el ámbito económico, el legado de Mayo del 68 también merecería ser retomado de cara a las gravísimas distorsiones de la economía actual, en particular, de la destrucción del medio ambiente (Jamail, 2019; Rich, 2019), de la profundización de la desigualdad (Alvaredo et al., 2018), de la extraordinaria concentración de poder en manos de pocas empresas (Vitali et al., 2011), y de la inadecuada, por no decir inexistente, rendición de cuentas de los directivos y ejecutivos de las grandes empresas (Ciepley, 2013; Deetz, 2007; Kuhn y Deetz, 2009; Wettstein, 2009). En este contexto vale la pena señalar que, si en la política hay una pandemia narcisista, en la economía parece haber una pandemia psicopática. El tema no se reduce a la presencia de psicópatas en los cargos de dirección de grandes empresas, un aspecto que ha sido abordado en la reciente literatura sobre psicología organizacional, y que de por sí es alarmante. ${ }^{23}$ Lo más grave tiene que ver con la tendencia de personas que, sin ningún desorden psicológico aparente, están dispuestas a comportarse como psicópatas, cuando toman decisiones cuya única consideración relevante es la maximización de las utilidades de los propietarios de la empresa. El acumulado de esas decisiones da lugar a que podamos clasificar el perfil de muchas empresas, si ellas tuvieran personalidad - no meramente personería jurídica- como entidades psicopáticas (Bakan, 2004). ${ }^{24}$ Los problemas enunciados al inicio de este párrafo guardan entre sí una conexión directa y bastante fuerte. Es muy probable que, en ausencia de la concentración de poder en manos de pocas empresas y de la irresponsabilidad con la cual son tomadas muchas de sus decisiones, la destrucción del medio ambiente y la profundización de la desigualdad no habrían tenido lugar o, al menos, no serían tan pronunciadas. 
Es evidente que la presión social, los incentivos legales, así como los del mercado no han sido suficientes para evitar decisiones irresponsables. En primer lugar, la presión social es esporádica, usualmente es reactiva y depende de los marcos mediáticos para activarse. En segundo lugar, la vigilancia de entidades públicas también es esporádica; si fuera continua, significaría una abrogación de la libertad de empresa. Finalmente, los incentivos del mercado usualmente operan en la dirección de ablandar las restricciones formales e informales a la obtención del lucro. ${ }^{25}$ Peor aún, el discurso de la llamada "responsabilidad social corporativa" y las prácticas asociadas a este discurso como las auditorías sociales y las recompensas a la conducta prosocial de las empresas contribuyen a generar la creencia equivocada de que los directivos y ejecutivos de las compañías sí toman en cuenta y responden a los intereses de las diferentes partes concernidas (Kuhn y Deetz, 2009). En respuesta a esta situación, ha surgido una teoría de la gerencia que plantea precisamente la inclusión de esas partes concernidas (en inglés, stakeholders) en la toma de decisión de las empresas (Freeman, 1984; Freeman y Reed, 1983; Freeman et al., 2010).

Los planteamientos de esta teoría convergen con los de la teoría política de la compañía (en inglés, corporation) (Ciepley, 2013). A diferencia de lo que postula la teoría liberal, la teoría política de la compañía plantea que no vivimos en un mundo en el cual nos relacionamos como individuos libres e iguales que intercambiamos bienes y servicios en el mercado. El mundo contemporáneo no se caracteriza por el paso del status al contrato, sino por el paso del contrato a la organización. Si bien las compañías operan en el ámbito del mercado, los individuos que toman las decisiones en esas compañías, operan en el marco de un contexto organizacional, lo que redunda en el hecho de que la mayoría de individuos nos relacionemos como tenedores de una posición laboral dentro de una organización. Muchas de estas organizaciones tienen la configuración de verdaderas repúblicas en el sentido de tener estructuras de gobierno basadas en su propia constitución o "carta" de autorización. No obstante, las declaraciones de derechos parecen no tener vigencia alguna en estas repúblicas. La distinción entre lo público y lo privado, así como la distinción entre el Estado y el mercado operan a favor de un ejercicio de poder comparable al de los estados absolutos, pues la gran mayoría de compañías funcionan internamente sin apego a ningún sentido de estado de derecho y, sobre todo, de democracia. De allí que uno de los planteamientos centrales de la teoría política de la compañía sea la pensarla, alternativamente, como una república de trabajadores (Ciepley, 2013, pp. 153-154).

Ciepley (2013) aclara que, en el ámbito de la empresa, el ejercicio de los derechos individuales podría ser regulado de cara a los fines económicos que aquella procura. Así, por ejemplo, la necesidad de defender los secretos comerciales daría lugar a refrenar el ejercicio irrestricto de la libertad de expresión. Sin embargo, de este derecho debería surgir una garantía institucional permanente para quienes alerten al público de fraudes en su contra (en inglés, whistleblowers), pues esa garantía interna de los trabajadores tornaría a ser un seguro externo de la sociedad contra decisiones irresponsables de muchas compañías. A la par con la institucionalización del estado de derecho dentro de la república empresarial podría institucionalizarse una forma de democracia de los trabajadores. Cipley resalta que estos pueden tener un interés mayor en la continuación de la operación de la empresa que el de los accionistas cuyos incentivos económicos están definidos por horizontes de corto plazo. Para los fines del punto considerado aquí, lo sustancial es que no habría ningún argumento político que permitiera derivar el despotismo de la gerencia de la propiedad de los accionistas. En este orden de ideas, sin abolir el mercado y la procura del lucro individual, sí podría retomarse uno de los postulados de la revuelta antijerárquica de Mayo del 68, a saber, la dirección de las industrias y de las empresas por las personas que trabajan en ellas.

Hoy la humanidad enfrenta varios desafíos que se superponen y que incluso se retroalimentan: una posible hecatombe nuclear, la extinción de la vida en el planeta, así como una grave dislocación social por efecto de la profundización de las desigualdades económicas y del uso de la inteligencia artificial en muchas esferas de la acción humana. Los escenarios apocalípticos han dejado de ser un tema de ficción para convertirse en caracterizaciones de nuestro futuro. De ahí que reverbere en esta hora el planteamiento de los estudiantes quienes, en la Declaración de Port Huron (Students for a Democratic Society, 1962), afirmaron, 
"Si parece que buscamos lo inalcanzable, como ha sido dicho, que se sepa que lo hacemos para evitar lo inimaginable" (Students for a Democratic Society, 1962). O, dicho en línea con la revuelta antijerárquica de Mayo del 68, ha llegado la hora de que seamos realistas y pidamos lo imposible.

\section{Referencias}

Abidor, M. (2018). May Made Me: An Oral History of the 1968 Uprising in France. Pluto Press.

Alvaredo, F., Chancel, L., Piketty, T., Saez, E., y Zucman, G. (2018). World Inequality Report. https://wir2018.wid.w orld/files/download/wir2018-summary-english.pdf

Aron, R. (1968a, 13 de junio). Raymond Aron analyse Mai 68. YouTube. https://www.youtube.com/watch?v=_Dz yjeuaDd 4

Aron, R. (1968b). La Révolution introuvable : Réflexions sur les événements de mai. Fayard.

Aron, R. (1977). Plaidoyer pour l'Europe Décadent. Éditions Robert Laffont.

Aron, R. (2005). Le Spectateur Engagé. Éditions de Fallois.

Aron, R. (2010). Mémoirs. Éditions Robert Laffont.

Babiak, P., y Hare. R. D. (2007). Snakes in Suits: When Psychopaths Go to Work. Harper Collins.

Bakan, J. (2004). The Corporation: The Pathological Pursuit of Profit and Power. Free Press.

Bénéton, P., y Touchard, J. (1970). Les interprétations de la crise de mai-juin 1968. Revue Française de Science Politique, 20(3), 503-544.

Besançon, J. (1968). “Les murs ont la parole”, journal mural, Mai 68. Tchou Éditeur.

Boddy, C. R., Ladyshewsky, R., y Galvin, P. (2010). Leaders without Ethics in Global Business: Corporate Psychopaths. Journal of Public Affairs, 10, 121-138.

Bourges, H. (1968). La révolte étudiante : les animateurs parlent. Éditions du Seuil.

Bowles, S., y Gintis, H. (1987). Democracy \& Capitalism: Property, Community, and the Contradictions of Modern Social Thought. Basic Books.

Castoriadis, C. (1986). Les mouvements des années soixante. Pouvoirs, 39, 108-116.

Ciepley, D. (2013). Beyond Public and Private: Toward a Political Theory of the Corporation. American Political Science Review, 107(1), 139-158.

Cohn-Bendit, D. (1968). Obsolete Communism: The Left-Wing Alternative. McGraw Hill.

Cohn-Bendit, D. (2013). Pour supprimer les partis politiques !? Réflexions d'un apatride sans parti. Indigène Editions.

Cohn-Bendit, D., Giraud, A., y Wiewiorka, M. (2018). El movimiento devorado por ideologías militantes. Debate entre Daniel Cohn-Bendit y Alain Geismar. Revista Mexicana de Ciencias Politicas y Sociales, 63(234), 343-357.

De Gaulle, C. (1968). Allocution radiodiffusée du 30 mai 1968. http://fresques.ina.fr/de-gaulle/fiche-media/Gaulle0 0366/allocution-radiodiffusee-du-30-mai-1968.html

Deetz, S. (2007). Corporate Governance, Corporate Social Responsibility, and Communication. En S. May, C. Cheney, y J. Roper (eds.), The Debate over Corporate Social Responsibility (pp. 267-278). Oxford University Pres.pp. 267-278.

Departamento de Estado de los Estados Unidos. (1968, 31 de mayo). Intelligence Memorandum. Foreign Relations of the United States, 1964-1968 (volumen XII). https://history.state.gov/historicaldocuments/frus1964-68v12 $/ \mathrm{d} 80$

Dogan, M. (1984). How Civil War Was Avoided in France. International Political Science Review, 5(3), 245-277.

Downs, A. (1957). An Economic Theory of Democracy. Basic Books.

Ferry, L. (1986). Interpréter Mai 68. Pouvoirs, 39, 5-13.

Ferry, L., y Renaut, A. (1990). French Philosophy of the Sixties: An Essay on Antibumanism. University of Massachusetts Press. 
Flacks, R., y Lichtenstein, N. (eds.). (2015). The Port Huron Statement: Sources and Legacies of the New Left's Founding Manifesto. University of Pennsylvania Press.

Freeman, E. (1984). Strategic Management: A Stakeholder Approach. Cambridge University Press.

Freeman, E., Harrison, J., Wicks, A., Parmar, B., y de Colle, S. (2010). Stakeholder Theory: The State of the Art. Cambridge University Press.

Freeman, E., y Reed, D. (1983). Stockholders and Stakeholders: A New Perspective on Corporate Governance. California Management Review, 25(3), 88-106.

Glucksman, A., y Glucksman, R. (2008). Mayo del 68: Por la Subversión Permanente. Taurus.

Golec de Zavala, A., Cichocka, A., Eidelson, R., y Jayawickreme, N. (2009). Collective Narcissism and Its Social Consequences. Journal of Personality and Social Psychology, 97(6), 1074-1096.

Gómez Albarello, J. G. (2019). Liderazgo sin líderes. Blogs El Espectador. http://blogs.elespectador.com/politica/cos mopolita/liderazgo-sin-lideres

Gregory, D. W. (2014). Unmasking Financial Psychopaths: Inside the Minds of Investors in the Twenty-First Century. Palgrave Macmillan.

Guerrero, A. (2014). Against Elections: The Lottocratic Alternative. Philosophy \& Public Affairs, 42(2), 136-178.

Jamail, D. (2019). The End of Ice: Bearing Witness and Finding Meaning in the Path of Climate Disruption. The New Press.

Julliard, J. (2013). Les gauches francaises 1762-2012. Flammarion.

Khodyakov, D. M. (2007). The Complexity of Trust-Control Relationships in Creative Organizations: Insights from a Qualitative Analysis of a Conductorless Orchestra. Social Forces, 86(1), 1-22.

Kolbert, E. (2014). The Sixth Extinction: An Unnatural History. Henry Holt and Company.

Korten, D. C. (2015). When Corporations Rule the World (3.. ed.). Berrett-Koehler Publishers.

Kuhn, T. R., y Deetz, S. (2009). Critical Theory and Corporate Social Responsibility: Can-Should We Get Beyond Cynical Reasoning. En A. Crane (ed.), The Oxford Handbook of Corporate Social Responsibility (pp. 174-203). Oxford University Press. pp. 174-203.

Laborit, H. (1976). Éloge de la fuite. Éditions Robert Laffont.

Le Goff, J. P. (2002). Mais 68, l'héritage impossible. La Découverte.

Lipovetsky, G. (1986a). La Era del Vacio: Ensayos sobre el Individualismo Contemporáneo. Anagrama.

Lipovetsky, G. (1986b). 'Changer la vie' ou l'irruption de l'individualisme transpolitique. Pouvoirs, 39, 71-79.

Lynd, S. (2010). The Cold War Expulsions and the Movement of the 1960s. En A. Grubacic (ed.), From Here to There: The Staughton Lynd Reader (pp. 96-107). PM Press.

Mair, P. (2013). Ruling the Void: The Hollowing of Western Democracy. Verso Books.

Malraux, A. (1968). Discours du 20 juin 1968 prononcé au Parc des expositions à Paris. Asamblée National. http://ww w.assemblee-nationale.fr/histoire/andre-malraux/discours_politique_culture/parc_expositions.asp

Margalit, A. (1998). The Decent Society. Harvard University Press.

Mason, P. (2015a). Postcapitalism: A Guide to Our Future. Allen Lane.

Mason, P. (2015b, 24 de mayo). How to turn a liberal hipster into a capitalist tyrant in one evening. The Guardian. http://www.theguardian.com/commentisfree/2015/may/24/turn-a-liberal-hipster-intoglobal-capi talist-world-factory

Meadows, D. H., Meadows, D. L. Randers, J., y Behrens, W. (1972). Los límites del crecimiento: Informe al Club de Roma sobre el Predicamento de la Humanidad. Fondo de Cultura Económica.

Mendel, A. P. (1969). Why the French Communists Stopped the Revolution? Review of Politics, 31(1), 3-27.

Minces, J. (1970). Réflexions autour du « journal de la Commune étudiante ». Sociologie et contestation, 16(1), 149-159.

Morin, E. (1986). Mai 68 : complexité et ambiguïté. Pouvoirs, 39, 71-79. 
Mujica, J. (2015). Jose's interview, Uruguay. Human, the movie. YouTube. https://www.youtube.com/watch?v=4GX 6a2WEA1Q

Post, J. (2015). Narcissism and Politics: Dreams of Glory. Cambridge University Press.

Rich, N. (2019). Losing Earth: A Recent History. Farrar, Strauss and Giroux.

Rihoux, B. (2016). Green party organisations: The difficult path from amateur-activist to professional-electoral logics. En E. Van Haute (ed.), Green Parties in Europe (pp. 298-314). Routledge. pp. 298-314.

Sabaneev, L. (1928). A Conductorless Orchestra. The Musical Times, 69(1022), 307-309.

Seifter, H., y Economy, P. (2001). Leadership Ensamble: Lessons in Collaborative Management from the Only Conductorless Orchestra. Henry Holt and Company.

Singer, D. (1970). Prelude to Revolution: France in May 68. Haymarket Books.

Sintomer, Y. (2011). Petite Histoire de l'Expérimentation Démocratique. La Découverte.

Students for a Democratic Society. (1962). Port Huron Statement. https://en.wikisource.org/wiki/Port_Huron_Sta tement

Tafurt, J. M. (2019). ¿Los colombianos somos (des)honestos? Ariel.

The Confessions of Congressman X. (2016). Mill City Press.

Tocqueville. T. (1850). De la Démocratie en Amérique. Pagneur Èditeur.

Twenge, J. M., y Campbell, W. K. (2009). The Narcissism Epidemic: Living in the Age of Entitlement. Atria Books.

Van Reybrouck, D. (2016). Against Elections: The Case for Democracy. Vintage.

Vitali, S., Glattfelder, J. B., y Battiston, S. (2011). The Network of Global Corporate Control. PLoS ONE, 6(10), e25995. https://www.ncbi.nlm.nih.gov/pmc/articles/PMC3202517/

Volkan, V. (2004). Blind Trust: Large Groups and Their Leaders in Times of Crisis and Terror. Pitchstone Publishing.

Vredenburgh, D., y He, I. Y. (2003). Leadership Lessons from a Conductorless Orchestra. Business Horizon, 46(5), 19-24.

Wallace, C. (2017). Down with Elections. C. Wallace.

Wettstein, F. (2009). Multinational Corporations and Global Justice: Human Rights Obligations of a QuasiGovernmental Institution. Stanford University Press.

Wikipedia. (2019). Soyez réalistes, demandez limposible. https://fr.wikipedia.org/wiki/Soyez_r \%C3\%A9alistes,_demandez_l\%27impossible

\section{Notas}

* Artículo de investigación.

1 Antonio Nariño (1765-1823) fue un político colombiano, prócer de la Independencia. En 1793 tradujo la Declaración de los Derechos del Hombre y del Ciudadano, promulgada por la Asamblea Nacional Constituyente de Francia el 3 de noviembre de 1789 .

2 André Glucksman presenta un punto de vista similar en su ensayo “Revoluciones y Contrarrevoluciones”, en el volumen conjunto de André y Raphaël Glucksman (2008), Mayo del 68: Por la Subversión Permanente. El título original de este volumen es Mai 68 expliqué à Nicolas Sarkozy.

3 El posmodernismo parece que alzó vuelo antes de Mayo del 68, y antes también de haber alcanzado su nombre. Por lo menos, eso es lo que nos da a entender Aron (1968b, pp. 122-123). Sus observaciones al respecto siguen siendo enteramente pertinentes: El desprecio de muchos renombrados intelectuales por los hechos ha alcanzado un grado increíble. En los medios parisinos, la fórmula "no hay hechos" tiene una aprobación completa. Bien entendida, no ignoro que en un cierto sentido la fórmula es filosóficamente verdadera: no hay hechos que no sean construidos; el hecho que encuentra el físico no existe sino en un sistema intelectual creado por la misma ciencia. En el estudio de la historia, no hay hechos que no hayan sido atrapados por la mirada del observador o reconstruidos a partir de documentos por el historiador. Conozco este tipo de reflexiones y, sobre todo, comencé mi carrera filosófica con especulaciones de esta suerte, pero en última instancia me siento tentado a jugar el papel de bruto y afirmar que toda sociedad está sometida a la coacción de los hechos, la necesidad de la producción, de la organización, de una jerarquía técnica, la necesidad de una 
tecno-burocracia, etc. A fuerza de sutileza, los intelectuales franceses terminan por olvidar las evidencias. La traducción es mía.

4 Este libro apareció en francés con el título Le gauchisme, remède à la maladie sénile du communisme, una parodia del título del opúsculo de V. I. Lenin, El izquierdismo, enfermedad infantil del comunismo.

5 Luc Ferry (1986) apela al método de análisis contrafáctico propuesto por Max Weber (el "experimento mental") para comprender el significado de los eventos. Sin embargo, no aplica este análisis a la minucia de los hechos. Si lo hubiera hecho, seguramente habría advertido que la convocatoria del Partido Comunista a la marcha y la huelga del 13 de mayo fue decisiva para que la revuelta estudiantil diera lugar a una situación revolucionaria.

6 Esta y otras entrevistas, así como un conjunto de documentos del movimiento estudiantil, fueron publicadas en junio de 1968 por Hervé Bourges en el volumen titulado La révolte étudiante: les animateurs parlent. El texto citado de CohnBendit aparece en la página 86. La traducción es mía.

7 Este memorando estaba archivado como secreto en la Biblioteca de Lyndon B. Johnson en el Volumen 13 de Archivos de Seguridad Nacional. Una nota indica que "fue preparado conjuntamente por la Oficina de Inteligencia Actual y la Oficina de Estimaciones Nacionales".

8 Aron (1968a) también expresó este punto de vista en una entrevista para la televisión suiza poco después de resuelta la crisis política. El segmento donde aparece es del minuto 12 en adelante.

9 Singer refiere la observación de Lucio Magri, dirigente comunista italiano, según la cual el Partido Comunista francés pudo haber obtenido varias concesiones del régimen entre las que se contaban la reforma a la ley electoral y la extensión del voto a los 18 años, de modo que los jóvenes, bastante activos en la crisis, se hubiesen volcado en favor de los comunistas. Magri también señaló que los comunistas pudieron haber demandado una reforma al Parlamento, que de Gaulle había reducido a su mínima expresión. Singer añade que la oposición pudo haber exigido también un cambio en el control de la radio y la televisión, que el régimen había utilizado para manipular la opinión. La ausencia de exigencias de este tipo permitiría inferir que el escenario que preveía el Partido Comunista, si la crisis se prolongaba, era la guerra civil y el aplastamiento de sus bases.

10 A esta misma conclusión llegó Arthur P. Mendel (1969) en su apreciación de las razones por las cuales los comunistas se negaron a seguir un curso de acción revolucionario.

11 Aron (2005, p. 364) reitera este punto en el diálogo con Jean-Louis Missika y Dominique Wolton.

12 Encuesta citada por Bénéton y Touchard (1970, p. 525).

13 Samuel Bowles y Herbert Gintis (1987, pp. 22, 138) han destacado esta segunda dimensión de lo político y su reducción a la primera.

14 En La révolution introuvable, Aron (1968b, p. 47) observa que, en el contexto de la disolución de las formas tradicionales de autoridad, individuos desarraigados terminan presos de accesos de fiebre "con un carácter esencialmente negativo, nihilista o destructor”. En esa misma obra, Aron (1968b, p. 31) refiere el aislamiento social de los estudiantes como uno de los mecanismos que los habría impulsado a una "especie de fraternidad juvenil en una comunidad semidelincuente". Más allá del juicio provocador, lo sustancial de la descripción es la experiencia de desarraigo, acentuada por la falta de contacto con profesores lejanos. A juzgar por uno de los grafitis de Mayo del 68 que puede considerarse emblemático, "Hábleles a sus vecinos", esta ausencia de vida comunitaria parece que era tan común entre los estudiantes como entre la mayoría de los ciudadanos, tan común quizá como lo es ahora.

15 Con respecto a este punto, Aron se refiere a la simultaneidad de los fenómenos aparentemente incompatibles de la licencia (laxitud, ausencia de restricciones, etc.) y la revuelta. Aquí creo que el ilustre sociólogo se equivocó en su apreciación pues la revuelta tenía como propósito realizar la licencia precisamente porque la sociedad despersonalizada era experimentada como excesivamente restrictiva.

16 Escribe Aron: ¿Por qué hombres cultos e inteligentes no pudieron resistirse a lo que me parece un delirio? ¿Por qué han olvidado de golpe la lección de todos los pensadores que han leído y han comentado eruditamente, de Aristóteles a Lenin, pasando por Maquiavelo y Marx? La explicación varía dependiendo de los individuos.... Los poetas de la revolución de mayo creyeron haber sobrepasado el marxismo; en la medida en que profesan ideas, han regresado al premarxismo, al socialismo utópico, olvidando un siglo de historia e ignorando las restricciones de la industria y de la economía. La traducción es mía.

17 A este respecto, hay un conjunto de grafitis que expresan, en forma de variaciones sobre un mismo tema, este sentido de una subjetividad desbordada, renuente a aceptar cualquier clase de restricción. Uno de ellos dice, “Tomo mis deseos por la realidad pues creo en la realidad de mis deseos”. Con ironía, la socióloga Juliette Minces (1970, pp. 150-151) observa, “¿No fue la frase clave de los estudiantes ‘Toma tus deseos por realidades'? Quizás esta es una de las explicaciones del poco cuidado que tenían los grupúsculos [estudiantiles] a la hora de analizar Francia en 1968, sus estructuras, su proletariado". A renglón seguido, Minces pone en cuestión la forma en la cual los protagonistas de la revuelta asumían, sin cuestionarse mucho, que la clase obrera tenía interés en una acción revolucionaria, cuando en realidad esa clase y todas las demás se beneficiaban del lugar de la Francia imperialista en la economía mundial. 
18 Este es un tópico común en la conversación social. Sobre este tema, una contribución reciente es la de Tafurt (2019). Con base en los planteamientos de Avishai Margalit (1998) acerca de la sociedad decente, en la literatura acerca de los efectos de la humillación en el comportamiento de los individuos, así como en encuestas relativas a la confianza interpersonal en Colombia y en otros países, Tafurt (2019) articula la conjetura de que la segregación colonial dio lugar al repertorio cultural de violación a las reglas al cual apelan muchos colombianos en la actualidad.

19 Este es uno de los slogans emblemáticos de Mayo del 68 (Besançon, 1968, p. 89), el cual ha sido objeto de muchos comentarios, tanto elogiosos como imprecativos (Wikipedia, 2019).

20 De manera bastante irónica y sarcástica, un autor anónimo (The Confessions of Congressman X, 2016) describió estas capacidades en el contexto de la vida política estadounidense. Su descripción, sin embargo, resulta aplicable a muchos otros contextos.

21 En su opúsculo Pour supprimer les partis politiques !?, Cohn-Bendit (2013, p. 20) escribe, Un partido es una armadura, una estructura cerrada, casi herméticamente sellada respecto de la sociedad. El debate político dentro suyo se limita esencialmente a cuestiones de organización, de repartición del poder, de estrategia y gestión de los diversos procesos más o menos democráticos que deben utilizarse. Y ahí es donde radica el problema: un partido captura gran parte de la energía de los activistas para resolver problemas internos. En un estilo totalmente diferente, también tenemos el 'modelo' del partido político que funciona como una 'máquina' electoral. El ejemplo típico es el Partido Demócrata estadounidense, una máquina diseñada principalmente para realizar elecciones, tomar el poder, tener funcionarios electos. El partido 'empresa' es otra versión. Utiliza y produce activistas profesionales que se dedican casi exclusivamente a la vida del partido. La traducción es mía.

22 Recientemente, la discusión acerca de la democracia por sorteo ha adquirido un inusitado vigor en ambos lados del Atlántico, como lo demuestran los trabajos de Guerrero (2014), Sintomer (2011), van Reybrouck (2016) y Wallace (2017).

23 Después de la publicación del trabajo seminal de Babiak y Hare (2007), Boddy et al. (2010) encontraron evidencia de que hay altos niveles de psicopatía en quienes ocupan cargos directivos en grandes empresas. Gregory (2014) concentró su atención en el caso del mundo financiero, donde encontró suficientes incentivos para seleccionar y promover a individuos con un perfil psicopático.

24 Richard Hare, a pedido de Bakan (2004, p. 56), hizo un perfil de las empresas que podrían ser clasificadas como psicópatas: serían aquellas que se comportan de modo irresponsable; que procuran manipularlo todo, incluida la opinión pública, y hacen de sí mismas descripciones grandiosas, al insistir que son las mejores en el mercado; que muestran una gran falta de empatía y tendencias asociales pues muestran un absoluto desinterés en la suerte de las personas afectadas por sus decisiones; que se niegan a aceptar responsabilidad por sus propios actos, son incapaces de sentir remordimiento, y que se relacionan con los otros de manera superficial. Todos los rasgos destacados en cursivas corresponden a características de personas psicópatas. El economista David C. Korten (2015) planteó el tema en su libro When Corporations Rule the World, publicado originalmente en 1995.

25 Paul Mason (2015b) refiere los resultados del experimento que tuvo lugar en el marco de la obra de teatro World Factory at the Young Vic, de Zoe Svendsen, estrenada en Londres en mayo de 2015. En esta obra la audiencia fue llamada a participar en la hipotética toma de decisiones de una empresa cuya planta de producción se encuentra en China. Cuando los participantes fueron sometidos a presiones de corto plazo consistentes en un bajo flujo de caja y una fuerte competencia, la gran mayoría tomó decisiones bastante rudas, en términos laborales e incluso éticos.

\section{Licencia Creative Commons CC BY 4.0}

Cómo citar este artículo: Gómez Albarello, J. G. (2020). Mayo del 68 y sus interpretaciones. Papel Político, 25. https://doi.org/10.11144/Javeriana.papo25.mdsi 